\title{
A Study of the Environmental Issues Associated with the Dominican Republic- Central American Free Trade Agreement (DR-CAFTA)
}

Shyamalendu "Sam" Sarkar, Saginaw Valley State University, USA

\begin{abstract}
The Dominican Republic-Central American Free Trade Agreement (DR-CAFTA) with the United States was passed on July 28, 2005. The main goal of DR-CAFTA is to create a free trade zone for economic development. The Agreement is highly controversial with many contentious issues including concern about the environment, which is the focus of this study. The concern is that the environmental objectives are expected to be subservient to trade and other economic incentives which will lead to further deterioration of the environment in countries where the environmental standards are already low. The effects on the U.S. environment are expected to be minimal. However, it is feared that the U.S. manufacturing facilities may relocate to Central American countries to take advantage of low wages and low environmental requirements, which may result in loss of jobs and capital investment in the U.S. However, overall DR-CAFTA is expected to be beneficial in many ways, including an increase in trade and economic growth in all participating countries.
\end{abstract}

\section{INTRODUCTION}

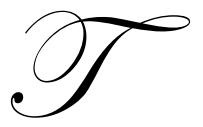

he Dominican Republic-Central American Free Trade Agreement (DR-CAFTA) with the United States was passed on July 28, 2005 and signed by President George W. Bush on August 2, 2005. Besides the US, the agreement includes Nicaragua, Costa Rica, Guatemala, El-Salvador, Honduras and the Dominican Republic, all who approved the agreement by October 7, 2007. The agreement is highly controversial and it passed in most countries by a very slim margin.

The goal of the agreement is to create a free trade zone similar to the North American Free Trade Agreement (NAFTA) between the United States, Canada and Mexico. However, besides trade issues, the agreement involved many other controversial issues relating to immigration, jobs, economic growth, democracy, freedom, investment, labor, environment, etc.

The present study focuses on the environmental issues associated with the DR-CAFTA. In recent years, different aspects of environmental problems have caused increased concern around the world. The impact on the environment was a major concern with NAFTA as well.

\section{ENVIRONMENTAL ISSUES}

Chapter 10 and specifically Chapter 17 of the DR-CAFTA Agreement outline the rules, regulations and other provisions for addressing the environmental issues. However, many economists, environmental groups and critics believe that the environmental provisions of DR-CAFTA lack sufficient standards and enforcement mechanisms toward environmental protection of the countries involved. Some of the criticism and concerns are as follows: 
- $\quad$ DR-CAFTA will lead to massive expansion of cruel and unsanitary "factory farms" in Central American countries and wipe out their traditional farming systems. This situation would result from the elimination of tariffs and sanitation requirements from US agricultural products and will allow massive imports of cheap meat and dairy products from the US. Further, as the Central American countries lack adequate water treatment facilities, the high volume of water needed to clean the "factory farms" ${ }^{1}$ would create a serious health hazard and environmental problems.

- $\quad$ DR-CAFTA provisions will also lead to deforestation and loss of habitat for a variety of migratory bird species and animals.

- $\quad$ Corporate investors could sue a country in international tribunals for huge compensation if they are not allowed to operate, even if their operation is destructive to the environment ${ }^{2}$.

- The region lacks even the most basic environmental laws necessary to protect forests, water supply, sanitation and biodiversity. The DR-CAFTA will bring about massive changes in industrial and agricultural development, possibly worsening the environmental situation.

- Under DR-CAFTA, countries are only required to enforce their existing laws. However, there are many loopholes in that provision, such as countries may use their available enforcement funds according to their own priorities, hence, not be able to address some of their existing provisions.

- $\quad$ "The recently appended Environmental Cooperation Agreement (ECA) fails to ensure anything more than the establishment of a multi-agency commission without even a required mandate for specific cooperative activities to improve environmental protection."

- $\quad$ "Although DR-CAFTA establishes a citizen submission process to allege enforcement failures, it does not provide for any clear outcomes or actions to actually ensure that citizens of the region can achieve enforcement of environmental laws. Moreover, the citizen submission process' lack of enforcement tools contrasts starkly with the monetary compensation that private investors can demand of governments under DR-CAFTA investor suit rules." 3

In the U.S., labor unions, politicians and others feared that the manufacturing facilities with high pollution indexes and high wages would have strong economic incentives to relocate to Central American countries to reduce their cost of production.

The criticism of the environmental provision of DR-CAFTA came from various corners for a variety of reasons. Although, these criticisms lessened the chance of passage of the Agreement, they also improved the awareness of people as well as members of the Senate and the Congress. To alleviate some of the perceived problems, additional safeguards were appended to the environmental provisions. It further ensured that a detailed environmental review be conducted by the U.S. government.

Environmental reviews are often conducted by agencies to ensure that policymakers and the public are educated about foreseeable environmental impacts of trade agreements, recognize the balance between trade and environmental objectives, and help identify appropriate responses if environmental impacts are recognized. Reviews are intended to help integrate environmental information and analysis into trade negotiations, while providing opportunities for public involvement and in-depth analysis. Generally, "reviews address two types of questions: (i) the extent to which positive and negative environmental impacts may flow from economic changes estimated to result from the prospective agreement; and (ii) the extent to which proposed agreement provisions may affect United States environmental laws and regulations." ${ }^{4}$

The United States Trade Representative was responsible for conducting a review of the possible environmental effects of DR-CAFTA globally, on the United States and the Central Americans region. In order to identify and examine all of the potential environmental effects that DR-CAFTA may have, the Administration collected public comments submitted in response to a published Interim Review. Comments were submitted by relevant advisory committees, the Trade and Environment Policy Advisory Committee, and relevant published economic analysis reports. The Administration found that the changes in trade flows as a result of the free trade agreement will not have any direct major environmental impact on the United States. However, the United States' environment may be vulnerable to indirect effects of the DR-CAFTA resulting from the transboundary transmission of air and water pollutants, such as through the effects on habitat for wildlife, including migratory species. The review examined all of the possible impacts from these factors, but did not identify any significant consequences for 
the United States' environment. It is mentioned in the review that these environmental effects must be continually monitored through existing domestic environment programs. The monitoring of these effects in Central America and the Dominican Republic will be further developed as a component of an Environmental Cooperation Agreement among the trading partners.

A high rate of deforestation has become a large threat to the ecosystem in Central America due to the large amounts of economic development and production that has been taking place. As a result, birds that fly south from the United States during the winter months to the Central American countries are losing their habitat. With the development of DR-CAFTA, the direct and indirect threats to survival of these birds may intensify. It will be important to consider this area of concern as a part of the environmental laws and enforcement within the Central American region. As mentioned above, another area of concern that indirectly affects the United States is the transboundary air pollution that blows from Central America. With no physical barriers to modify or impede them, air masses from Central America and the Dominican Republic have an unobstructed path northward as far as the Great Lakes. The large amounts of air pollution are a result of agricultural burning and clearing of land using fire, a common practice in Central America. Policies are being developed by countries in the region to help reduce the frequency and extent of burning, which have a large impact on the air quality in both the region and the United States. As the economy in Central America picks up, so will the amount of pollutants that are emitted into the environment. As a result, it is important for countries in the Central American region to establish and enforce environmental standards and find ways to develop environment-friendly production practices.

The environmental review provided by the Administration also found that DR-CAFTA will not conflict with the ability of United States federal, state, local, or tribal governments to regulate or protect their environments. The goal of the DR-CAFTA provisions is to create positive propositions for the enforcement of environmental laws and the continual development of environmental protection in both the United States and the Central American countries and the Dominican Republic. It is likely that the economies and environments of the Central American countries and the Dominican Republic will be influenced more greatly and easily than that of the United States. The DR-CAFTA should increase investment, trade, and production in the Central American region, which will in turn create additional pressures on the environment. The effect of these pressures can be very harmful to the environment for the Central American countries, largely due to the fact that they contain a considerable amount of biological diversity. The marine and coastal systems of the region create a complex ecosystem that is among the most productive in the world. Under the existing situation, ongoing habitat loss threatens many species, and a variety of activities, such as resource extraction, land conversion for agriculture, coastal development, and tourism are causing degradation of terrestrial and marine ecosystems. The most common environmental problems are the loss of biodiversity due to deforestation and forest degradation; air and water pollution; waste disposal; sustainable energy production; and degradation of land through erosion, nutrient depletion and mismanagement. With the added pressure from investment, trade, and ongoing development in the region, it creates a difficult challenge for environmentalists to manage the environment effectively and efficiently. Their ability to implement and enforce environmental laws will play a large role in the preservation of the regional ecosystems.

It will be important to create positive environmental changes in the Central American countries by reinforcing efforts to effectively enforce environmental laws, accelerating economic growth and development through trade, investment, and disseminating environmentally beneficial technologies. These countries are currently progressing in the development of appropriate environmental laws and towards creating stronger enforcement mechanisms. These efforts have been achieved through an initial concentration on particular environmental sectors and the development of a systematic identification of objectives and standards.

In addition to the DR-CAFTA, the United States, Central American countries, and the Dominican Republic have created additional agreements that complement the original free trade agreement. These provisions of the trade agreement strive to ensure that they do not weaken or reduce the protections afforded in domestic environmental laws as an encouragement for trade. They have already signed an Environmental Cooperation Agreement (ECA), which provides a comprehensive structure for developing cooperative activities. The agreement constructs detailed provisions for benchmarking and monitoring the progress of the cooperative activities. These activities include: (1) implementation of a budget strategy to ensure that priorities are identified in the ECA and their work plans are fully funded; (2) establishment of short, medium, and long term goals for improvements in environmental protection in 
the Central American region; (3) creation of opportunities to increase regional coordination of activities and natural resources; (4) promotion of clean technologies and environment-friendly goods and services; and (5) implementation and enforcement of environmental laws, and the regulation of obligations under certain multilateral environmental agreements, etc. An Environmental Cooperation Commission that consists of high-level officials with environmental responsibilities from each Party will administer the execution of the ECA.

The US government has provided significant funds towards helping to improve environmental laws, area protection, fisheries enforcement, wildlife management capacity, and compliance strengthening with the Convention on International Trade in Endangered Species (CITES) for DR-CAFTA countries. The CITES is a multilateral environmental agreement appended to the Environmental Cooperation Agreement. The goal of these organization and committees is to ensure that parties do not fail to effectively enforce environmental laws through a sustained or recurring course of action or inaction. Hopefully, the United States' help in developing the economic structure, environmental organization, and related committees within the Central American region will create an economy and environment that is capable of producing at a rapid rate of growth. The growth of the economic industry in the region must be complemented with a strong political structure, judicial system, and environment that can handle the increased levels of growth. The enhancement in the capacity of these trading partners will help protect the environment through the promotion of sustainable development. The result will be the reduction or elimination of government practices and policies that threaten sustainable development, while opening up market access for environmental technologies, goods, and services for the United States. In 2005, the United States Trade Representative, Rob Portman, stated that "the Bush Administration was hoping to commit $\$ 180$ million in funds over the next five years to help improve workers' rights and environmental protection in the CAFTA countries." ${ }^{5}$ The goal of this funding is to further enhance the capacities of the Central American countries and the Dominican Republic in adopting more effective and accountable approaches in enforcing environmental laws.

\section{CONCLUSION}

It should be clear from the main goal of DR-CAFTA, that the environmental objectives are subservient to the trade and economic growth of the nations involved. May be a race to the environmental bottom can be avoided, but virtually no one expects that environmental conditions in Central America will improve as a result of the Agreement in the short-run.

The completion of DR-CAFTA has received many mixed opinions from economists, environmental organization, and critics throughout the world. Despite the failure to have greatly detailed literature in the environmental chapter of the trade agreement, numerous steps have been taken since the initial signing of the agreement to address the issues of concern. DR-CAFTA is one of the first trade agreements to address a number of environmental issues in its core text and has provided a great number of benchmarking and monitoring provisions of environmental planning and activities. The United States has taken initiatives to conduct environmental reviews, develop complementary agreements to DR-CAFTA, and provide funding to DR-CAFTA countries to help develop organizations, committees, and the internal structures of Central American countries and the Dominican Republic. The United States is continuing to ensure that trade and environmental policies are mutually supportive, seek to protect and preserve the environment, and enhance the international means of doing so, while optimizing the use of the world's resources. It will be important for the United States to continue stressing the importance of establishing and enforcing environmental laws of countries in the Central America region, who will likely notice great changes in their economic and environmental structures as a result of the continual development of the DR-CAFTA. Not only will the support and leadership provided by the United States help each of the participating DR-CAFTA countries environmental and economic structures, but it will also help to solidify each country's political, social, and physical well-being for many years to come.

\section{SUGGESTIONS FOR FUTURE RESEARCH}

Environmental issues are becoming increasingly important in international trade and in political and economic discussions around the world. It will take several years before the actual environmental impact of DRCAFTA can be assessed. However, such assessments are vital for the protection of the environment. Hence, future research in this area should focus on estimating the actual impact of the Agreement on overall the environmental 
quality of the participating countries. The research is expected to generate information that will be highly useful in crafting future free trade agreements which are consistent with preserving the environmental quality of nations involved.

\section{AUTHOR INFORMATION}

Shyamalendu "Sam" Sarkar, Earned Ph.D. (1969) from Michigan State University in Ag. Economics. Currently, Professor of Economics, College of Business and Management. Chair of Economics Department for 25 years and Director of MBA program for five years.

Received Outstanding Teacher Award from the University as well as from the Legislature, State of Michigan. Also received Outstanding Research Award from the University.

Have published 26 articles in refereed professional journals. Attended and presented about 38 research papers in professional conferences. Have provided significant service to the University and the community at large.

\section{ENDNOTES}

${ }^{1}$ Raising farm animals under intensive confinement.

${ }^{2}$ Based on comments from Adam Weissman.

${ }^{3}$ The above four paragraphs are based upon the testimony of David F. Waskow, Director of the International Program Friends of the Earth.

${ }_{5}^{4}$ Office of the United States Trade Representative.

${ }^{5}$ Fact Sheet (2005)

\section{BIBLIOGRAPHY}

1. Cevallos, Diego. The "Green" Promises of CAFTA. Inter Press Service, February 17, 2005. Proquest Database.

2. Fact Sheet: CAFTA-DR Labor and Environment Projects. US Fed News Service, Including US State News. Washington, D.C.: September 28, 2006.

3. Office of the United States Trade Representative. Environmental Firsts in CAFTA: New CitizenParticipation Process, Benchmarking of Progress. February 2005. www.ustr.gov.

4. Office of the United States Trade Representative. Final Environmental Review of the Dominican-RepublicCentral America-United States Free Trade Agreement. February 2005. www.ustr.gov.

5. The Dominican Republic-Central America-United States Free Trade Agreement, Master document signed by all countries by October 7, 2007.

6. US Supports Better Labor, Environment Efforts in CAFTA Nations. US Fed News Service, Including US State News. Washington, D.C.: July 19, 2005.

7. Waskow, David F. Testimony given before the Subcommittee on Commerce, Trade and Consumer Protection of the House Committee on Energy and Commerce, April 28, 2005.

8. Weissman, Adam. People's Weekly World Newspaper, 08/25/05 20:57. The article found at www.pww.org.

9. White, Stephanie. First NAFTA, Now CAFTA? E: The Environmental Magazine. Norwalk: July/August 2005. Vol. 16, Iss. 4. 
NOTES 